\title{
Population health and the economy: Mortality and the Great Recession in Europe
}

\author{
José A. Tapia Granados ${ }^{1}$ (I) । Edward L. Ionides ${ }^{2}$
}

${ }^{1}$ Politics, Drexel University, Philadelphia, USA

${ }^{2}$ Statistics, University of Michigan, Ann Arbor, Michigan, USA

\section{Correspondence}

José A. Tapia Granados, Politics, Drexel University, 3141 Chestnut Street, MacAlister Hall 3021-E, Philadelphia 19104, USA.

Email: jat368@drexel.edu

\begin{abstract}
We analyze the evolution of mortality-based health indicators in 27 European countries before and after the start of the Great Recession. We find that in the countries where the crisis has been particularly severe, mortality reductions in 2007-2010 were considerably bigger than in 2004-2007. Panel models adjusted for spaceinvariant and time-invariant factors show that an increase of 1 percentage point in the national unemployment rate is associated with a reduction of $0.5 \%(p<.001)$ in the rate of age-adjusted mortality. The pattern of mortality oscillating procyclically is found for total and sex-specific mortality, cause-specific mortality due to major causes of death, and mortality for ages 30-44 and 75 and over, but not for ages $0-14$. Suicides appear increasing when the economy deceleratescountercyclically - but the evidence is weak. Results are robust to using different weights in the regression, applying nonlinear methods for detrending, expanding the sample, and using as business cycle indicator gross domestic product per capita or employment-to-population ratios rather than the unemployment rate. We conclude that in the European experience of the past 20 years, recessions, on average, have beneficial short-term effects on mortality of the adult population.
\end{abstract}

\section{KEYWORDS}

recessions, Great Recession, Europe, mortality rates, life expectancy at birth, population health

\section{1 | INTRODUCTION}

Political and economic upheavals experienced by European countries in the past 3 decades provide substantial material to investigate the influence of social and economic conditions on health. This article focuses on the Great Recession, a global economic and financial crisis (Kose \& Terrones, 2015) that was particularly severe in many European countries, where there were big increases in unemployment (Figure 1), as well as generalized banking problems, large public and private debts, and austerity policies that have created serious social distress and major financing problems for public services, including health care. Previously, in the early 1990s, the breakdown of the Soviet Union and the transition to a market economy in the former centrally planned economies of Eastern and Central Europe were the occasion for major downturns of population health-with large increases of mortality rates in all countries of the old Soviet bloc (Cornia \& Paniccià, 2000). Contrarily, in Western Europe, the 1990s saw steady improvements of health conditions, as it is clearly illustrated by the evolution of life expectancy at birth ( $e_{0}$ in demographic notation), life expectancy at $65\left(e_{65}\right)$, and infant mortality rates (Figures 2-4). The 21st century started with a recession that was generally mild in most European countries, implying moderate increases in unemployment rates (Figure 1). The following economic expansion ended in late 2007, and then economic conditions deteriorated rapidly with many European countries suffering a severe downturn of economic activity with soaring unemployment. Somewhat surprisingly, the health 


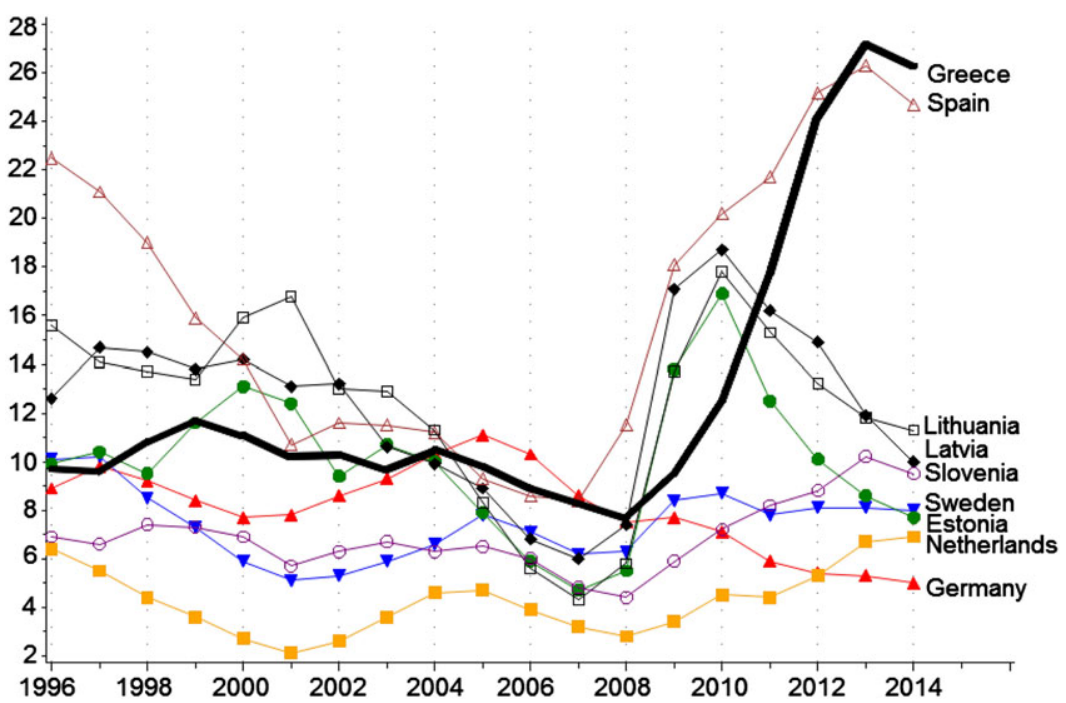

FIGURE 1 Unemployment rates (as percentage of the economically active population) of nine European countries, 1996-2014. Data source: World

Development Indicators

effects of the Great Recession in Europe have been controversial. Initial reports of harmful effects of the recession on health and health care in Europe in general or in specific European countries (Kentikelenis et al., 2014; Karanikolos et al., 2013; Simou \& Koutsogeorgou, 2014) were questioned (Liaropoulos, 2012; Tapia Granados \& Rodriguez, 2015), and several authors have found that apparently, the recession is having beneficial effects on health (de la Fuente et al., 2014), particularly on major indicators of population health, including general mortality (Regidor et al., 2016; Toffolutti \& Suhrcke, 2014). After 2010, the available data for both $\mathrm{e}_{0}$ and $\mathrm{e}_{65}$ reveal continuous improvement-though Germany is an exception (Figures 2 and 3 ).

The unemployment rate has been often used as business cycle indicator in studies to ascertain the impact of the business cycle on mortality rates. Studies of different countries and periods have usually found that once long-term trends are adjusted for, general mortality and mortality due to major causes of death tend to decrease in recessions, that is, when the unemployment rate is rising (e.g., Eyer, 1977a; Gerdtham \& Ruhm, 2006; Haaland \& Telle, 2015; Ogburn \& Thomas, 1922; Ruhm, 2000, 2007, 2015a, 2015b; Tapia Granados \& Diez Roux, 2009). On the other hand, in studies on individuals, it has been often found that the risk of death differs between jobless individuals and employed ones (Kasl \& Jones, 2000), with unemployed having a higher risk of death compared to their employed counterparts (e.g., Sullivan \& von Wachter, 2009; Burgard, Brand, \& House, 2009). These opposing effects of individual unemployment and contextual unemployment are not inconsistent and have been observed to operate concurrently when individual-level data are linked to population-level data (Tapia Granados et al., 2014). Confusion has been often created by the fact that in some reviews of this kind of literature (e.g., Catalano et al., 2011), terms such as "economic decline" or "unemployment" have been used indistinctively and imprecisely to mean specific individuals suffering unemployment or individuals in populations exposed to a high-unemployment rate.

A consensus seems to be emerging that, at the level of individuals, ill health and joblessness are likely to be linked by bidirectional causality. This implies that causality probably exists from joblessness to higher risk of disease and death, and in the opposite direction, from ill health to higher risk of becoming unemployed. Studies that have tried to disentangle these causal effects suggest that indeed unemployment raises the risk of disease or death in individuals who suffer it (Burgard et al., 2009; Sullivan \& von Wachter, 2009; Tapia Granados et al., 2014), as well as ill health raises the probability of becoming unemployed (Martikainen \& Valkonen, 1996; Valkonen \& Martikainen, 1996). On the other hand, the pattern of mortality rising over trend in periods of prosperity and falling below trend in recessions, that is, oscillating procyclically, has been found in a variety of high-income market economies (Ogburn \& Thomas, 1922; Tapia Granados \& Diez Roux, 2009; Eyer, 1977a; Ruhm, 2000; Gerdtham \& Ruhm, 2006; Ruhm, 2007; Haaland \& Telle, 2015; Sen, 2001; Tapia Granados, 2005, 2008, 2012; Tapia Granados \& Ionides, 2008, 2011; Neumayer, 2004; Rolden et al., 2014; Lindo, 2015) as well as some middle-income economies (Abdala et al., 2000; Gonzalez \& Quast, 2010a, 2010b; Lin, 2009). In many of these studies in which total mortality and mortality due to major causes of death have been found to oscillate procyclically, a countercyclical oscillation has been found in suicide rates, which usually rise when the economy deteriorates.

In this paper, we use a variety of mortality-based health indicators to describe the evolution of population health in Europe before and after the start of the Great Recession. A variety of methods are used to investigate the relation between economic conditions and changes in mortality-based indicators in the years after the turn of the century. We obtain consistent results across the general population, male and female subpopulations of males and females, and different age strata. Given the data 


\section{Unemployment Increase $<2$ p. p.}

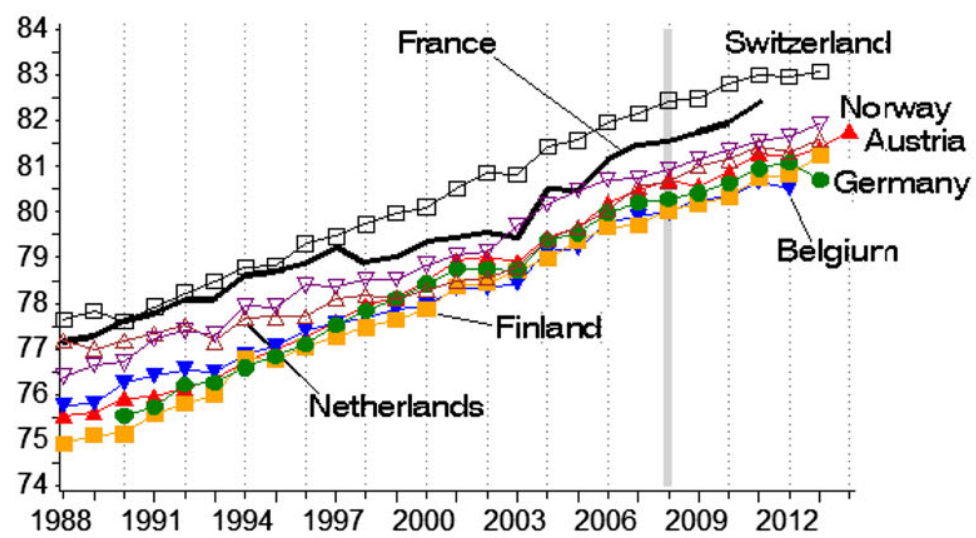

Unemployment Increase 2 to 4 p. p.

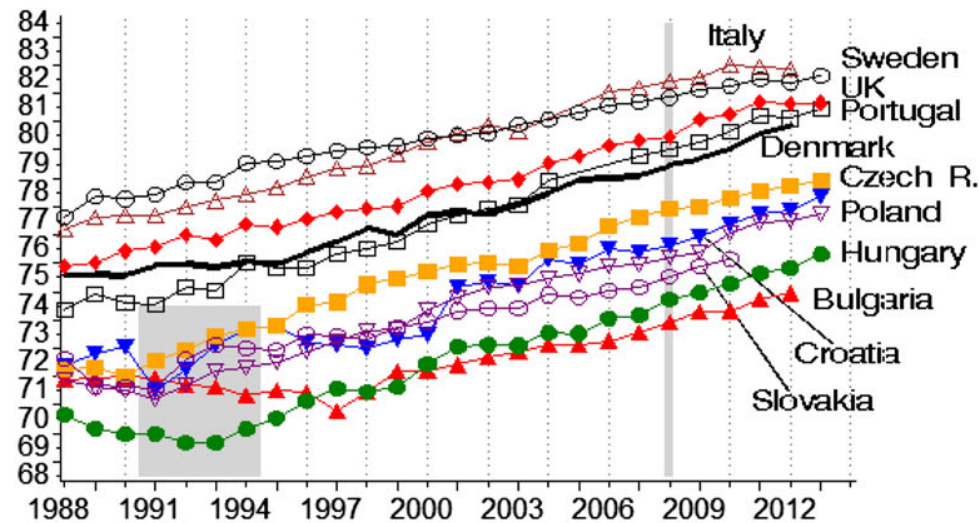

FIGURE 2 Life expectancy at birth (years) in 27 European countries sorted by the unemployment increase (in percentage points, p. p.) between 2007 and 2010. The recession was mild in the countries included in the upper panel, moderately severe in the countries of the mid panel, and severe in the countries of the bottom panel. In that panel, the gray rectangle in the early $1990 \mathrm{~s}$ corresponds to the transition to a market economy in Eastern European countries. The gray vertical bar in the three panels represents the start of the Great Recession. Data source: European Health For All Database

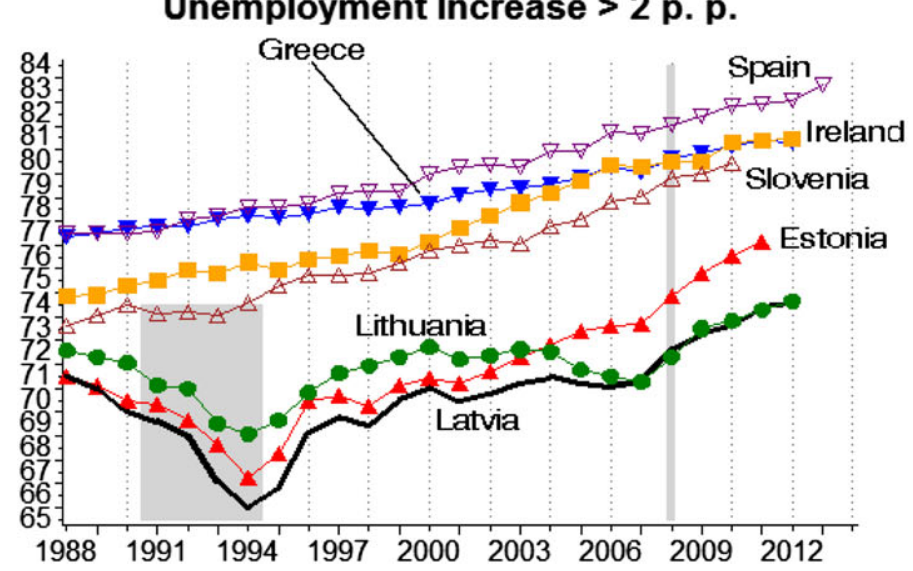

used and the analysis we have done, we cannot compare the effect of economic conditions on health across socioeconomic groups, or in employed and unemployed people.

\section{2 | DATA}

This investigation comprises 27 European countries with population over a million. That includes 25 members of the European Union - all European Union members except Luxemburg, Malta, and Cyprus—plus Norway and Switzerland. Data come from three databases, the European Health for All Database (WHO Regional Office for Europe, 2016a), the European Health for All Mortality Database (WHO Regional Office for Europe, 2016b), and the World Development Indicators (World Bank, 2016). 

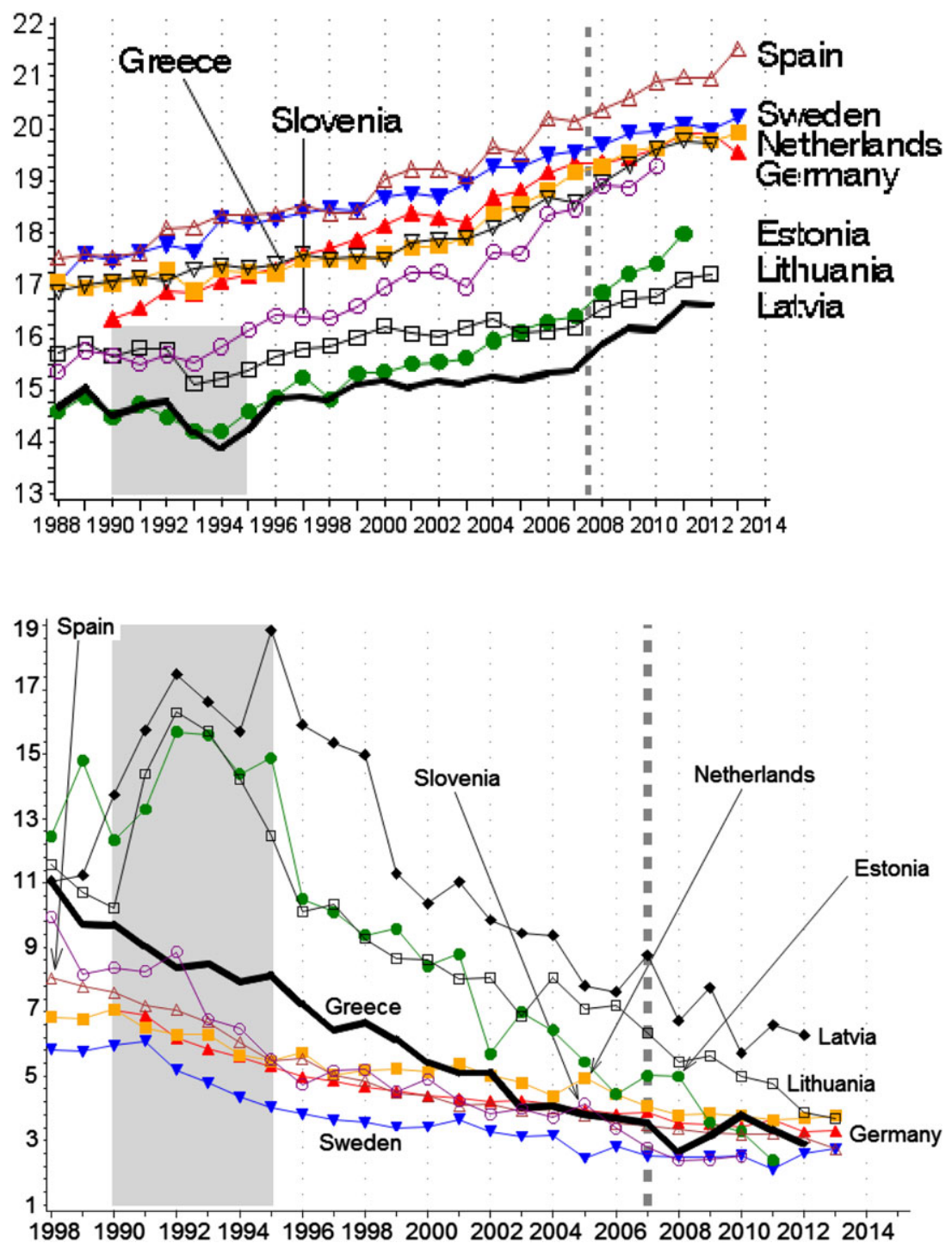

FIGURE 3 Life expectancy (years) at age 65 in nine European countries. The shaded area in the early 1990s represents the transition to a market economy in Eastern Europe; the start of the Great Recession is represented by a dashed vertical line. Data source: European Health For All Database
FIGURE 4 Infant mortality rate (deaths of children younger than 1 per 1,000 live births) in nine European countries. The shaded area in the early 1990s represents the transition to a market economy in Eastern Europe; the start of the Great Recession is represented by a dashed vertical line. Data source: European Health For All Database

Our investigation focuses mainly on life expectancy at birth, $e_{0}$, as the indicator that summarizes mortality at all ages and is increasingly utilized as the best comprehensive indicator of population health for intertemporal and crossnational comparisons (Riley, 2001; Sen, 2001; Szreter \& Mooney, 1998). But for the sake of comprehensiveness, we examine a set of 15 indicators of population health. They include general and sex-specific $e_{0}, e_{65}$, infant mortality, and age-standardized death rates for all causes, for six major causes of death, and for ages 0-14, 30-44, and 75 and over. Cause-specific mortality rates that we investigated include six major causes of death: cardiovascular disease (CVD) and a subset of it, ischemic heart disease (IHD), respiratory disease, transportation injuries, infectious and parasitic disease, and suicide. We used the national unemployment rate-which is a lagged countercyclical indicator of the business cycle that rises some quarters after the recession has started-as main indicator of macroeconomic conditions. But we also used the employment-to-population ratio and gross domestic product (GDP) per capita as explanatory variable indexing macroeconomic conditions. Appendix A includes all data used in the analysis and further details on data sources.

\section{3 | METHODS}

Data downloaded from the European Health for All Database in March 2016 are relatively complete for health indicators up to 2013, but not for later years (Figures 1-3). For our descriptive analysis, we consider that 2007 was the last year of the expansion before the recession openly started in most European countries in 2008. Thus, we compare the improvement in population health - as measured by the gain in $e_{0}$-in the 3-year period 2007-2010 (recession period) with the improvement in the previous 3-year 
period 2004-2007 (prerecession or expansion period) in the 26 countries of our general sample for which $e_{0}$ data are available for the years 2004, 2007, and 2010 (Table 1). Then we compare the evolution of the 16 indicators of population health in 2004-2007 and 2007-2010 in the 27 countries of our sample classified according to the severity of the crisis (Table 2).

Regression models are used to test whether the change in economic conditions is associated with changes in health indicators (Tables 3 and 4). For our regression analyses, which do not imply any assumption on the dating of the recession, we use the 27 countries during the period 2004-2010, and we check the robustness of the results to sample selection by expanding the panel to the whole decade since the start of the century, as well as to two longer periods: 2000-2013 and 1995-2013. We do not expand the panels further backward to the early 1990s to avoid including the years of transition to a market economy in the countries of Eastern Europe that were associated with major increases in mortality (Cornia \& Paniccià, 2000).

Significant correlations between time series with trends are usually meaningless in terms of causality (Diggle, 1989; Gujarati, 2003). Series need to be prewhitened to avoid spuriously significant results in statistical tests. Different methods can be used for prewhitening; the most common procedures imply just eliminating the trends, detrending the series. ${ }^{1}$ We present here the results for panel regressions with fixed effects for countries and years and country-specific linear trends (Table 3), as well as results for models with nonlinear detrending (Table 4, see also Appendix B for details). Nonlinear detrending analysis is arguably preferable (Ionides et al., 2013), but here, we keep linear detrending as our primary analysis for the benefit of simplicity.

In our main regression models, the dependent variable $h_{t j}$ is a health indicator (or its natural logarithm) for year $t$ and country $j$. The model equation is

$$
h_{t j}=\alpha+\beta U_{t j}+\Pi_{t}+\Omega_{j}+\gamma_{j} t+\varepsilon_{t j}
$$

where $U_{t j}$ is the unemployment rate for country $j$ in year $t, \Pi_{t}$ and $\Omega_{j}$ are dummies for year and country, $\gamma_{j}$ is the slope of a country-specific time trend, and $\varepsilon_{t j}$ is the error term. Observations were weighted by the square root of the population weight to compensate for heteroskedasticity.

The fixed effects $\Pi_{\mathrm{t}}$ and $\Omega_{\mathrm{j}}$ for year and country and the country-specific linear trends give some protection against biases linked to the influence of omitted variables, known as "confounders" in epidemiological terminology. Time-fixed effects estimated by including a year dummy in the model adjust for space-invariant factors that differ across time (say mild temperatures in winter in all European countries during the Great Recession potentially causing lower rates of respiratory disease mortality), while country-fixed effects adjust for time-invariant factors that differ across countries (say higher alcohol consumption in some countries compared with others). Country-specific linear trends protect against the influence of potential confounders that change slowly and can be approximated with a linear trend (Ruhm, 2000).

Variables related to economic activity, such as air pollution, are not appropriate as covariates in the regression model because they are conceivably the mechanisms for which unemployment fluctuations are a proxy. Including in the model two measurements of the same phenomenon, weak identifiability would be expected. Since all quantities fluctuating with the business cycle are correlated, we use one such measure in the model as a proxy for all potential causal mechanisms (Ionides et al., 2013). Our analysis investigates the evidence for the existence of cyclical mortality, which is prerequisite for further study of the mechanisms.

\section{4 | DESCRIPTIVE ANALYSIS}

Unemployment rates rapidly increased in 2007-2010 (Table 1, Figure 1), but health indicators (Figures 2-4) continued improving, with $e_{0}$ and $e_{65}$ rising even faster in countries such as the Baltic states, Spain, or Greece, strongly affected by the economic crisis (Figures 2 and 3). Considering the 26 countries for which $e_{0}$ data are available for 2004, 2007, and 2010, $e_{0}$ grew both in 2004-2007 and in 2007-2010, with the only exception of Lithuania and Latvia, where $e_{0}$ had decreased in the period 20042007 previous to the crisis (Figures 2 and 5, upper panel). In this period of declining $e_{0}$-which implies rising mortalitythe economy of these two Baltic nations had had a boom, with GDP growth reaching phenomenal rates of $12.2 \%$ in Latvia in 2006 and $9.8 \%$ in Lithuania in 2007.

Both in 2004-2007 and 2007-2010, there is a positive and significant correlation between the change in unemployment, $\Delta U$, and the change in life expectancy at birth, $\Delta e_{0}$. Considering the changes either in 2004-2007 or in 2007-2010, the Pearson correlations are respectively $r=0.56(p=.003$, Figure 5, upper panel) and $r=0.83(p<.0001)$. When the correlations are

${ }^{1}$ Differencing is the simplest detrending method and the one that was used in this investigation for some correlations. In our regression analysis, trends were taken care of by using panel analysis with (a) fixed effects for year and state; (b) fixed effects for year and state plus country-specific linear trends; (c) variables transformed by nonlinear detrending; and (d) variables in differences and fixed effects for years only. These are standard methods that have been previously used for similar purposes (Gerdtham \& Ruhm, 2006; Ionides et al., 2013; Neumayer, 2004; Ruhm, 2000). We obtained quite similar results using these four types of models. 
TABLE 1 Life expectancy at birth ( $e_{0}$, in years) and unemployment rate $(U, \%)$ in 2004, 2007, and 2010 in 27 European countries. $\Delta e_{0}$ and $\Delta U$ are the changes (between 2004 and 2007 and between 2007 and 2010) in both variables

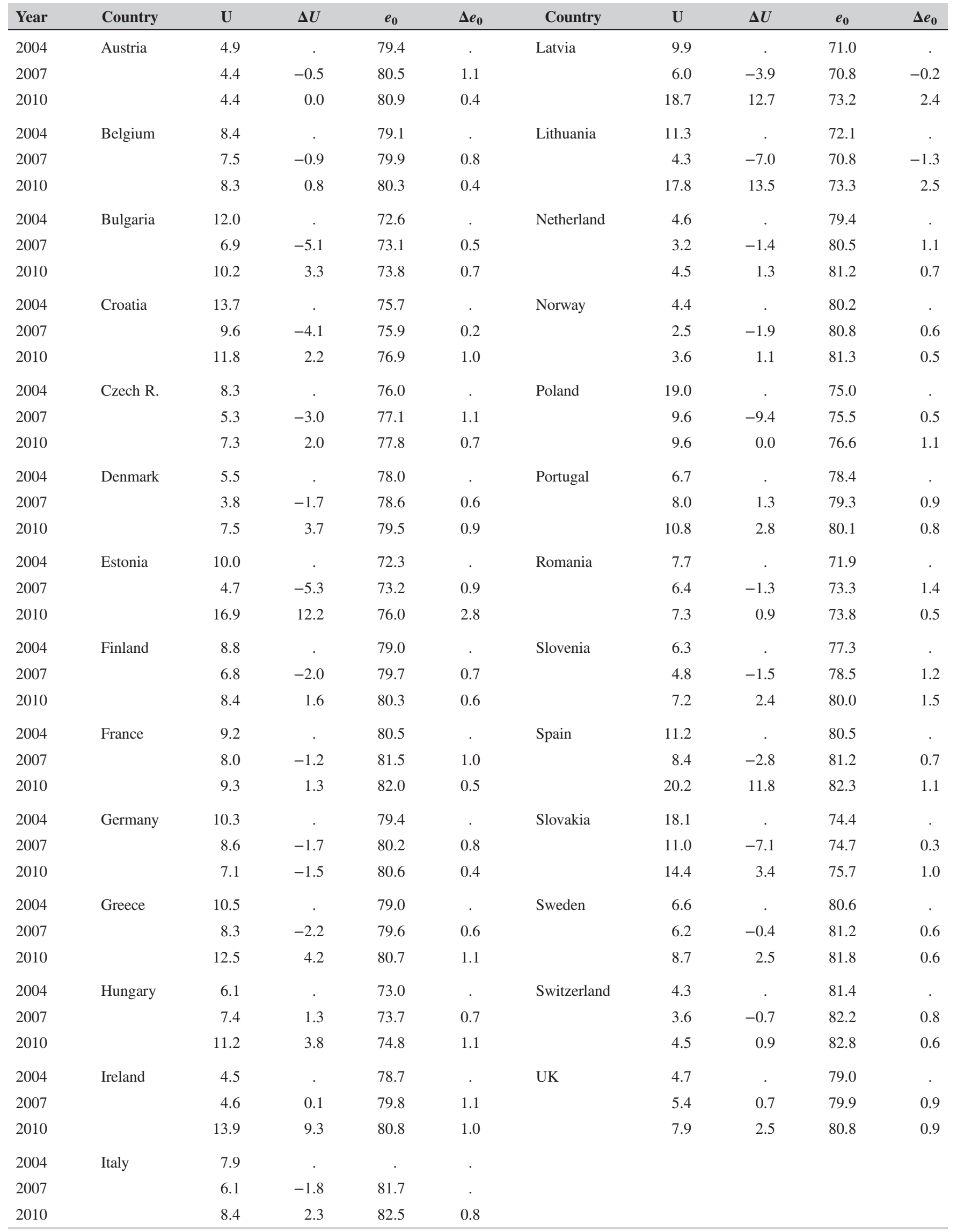




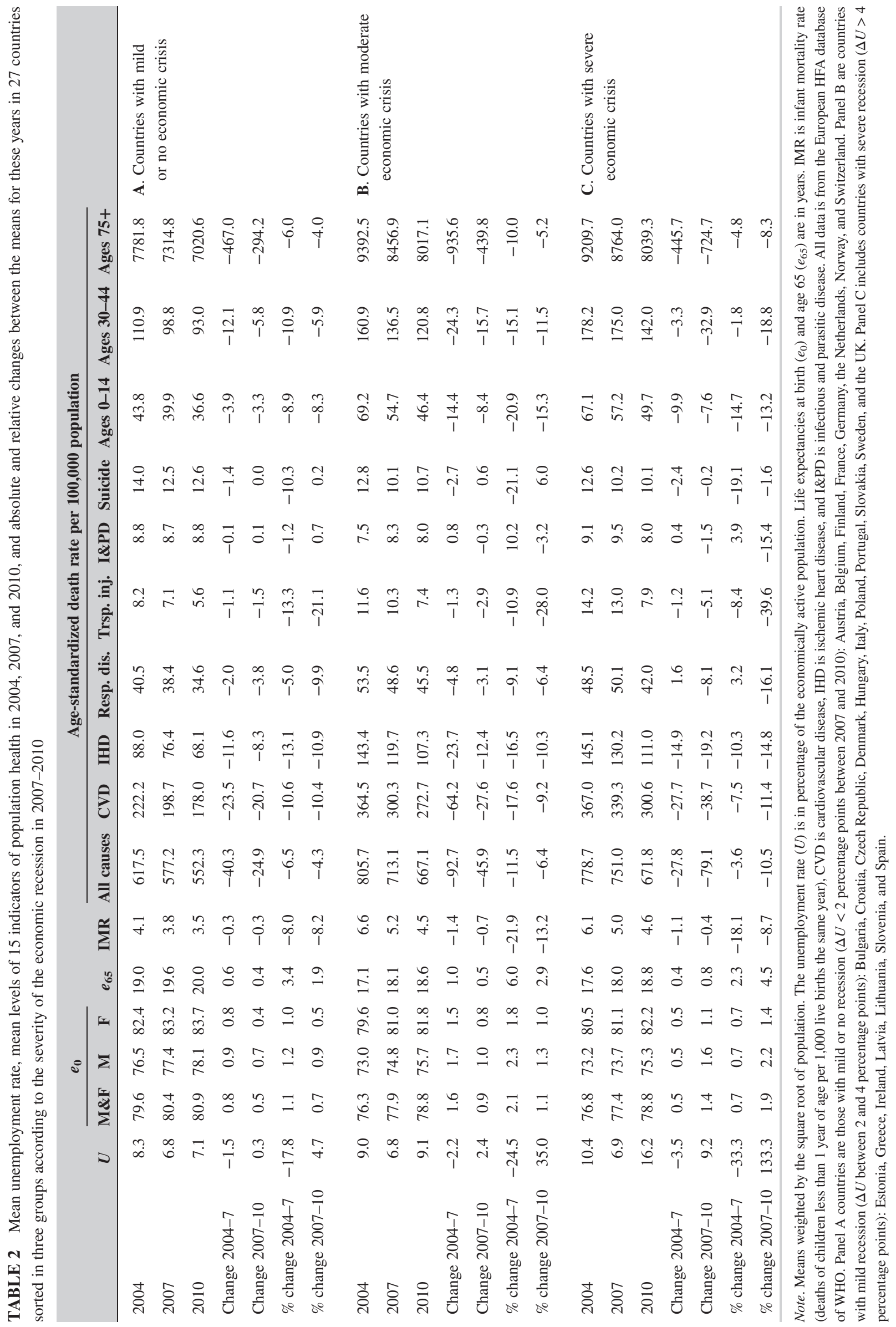


TABLE 3 Regression estimates of the change in an indicator of population health associated with a percentage point increase in the unemployment rate. Data for 27 European countries in the specified years

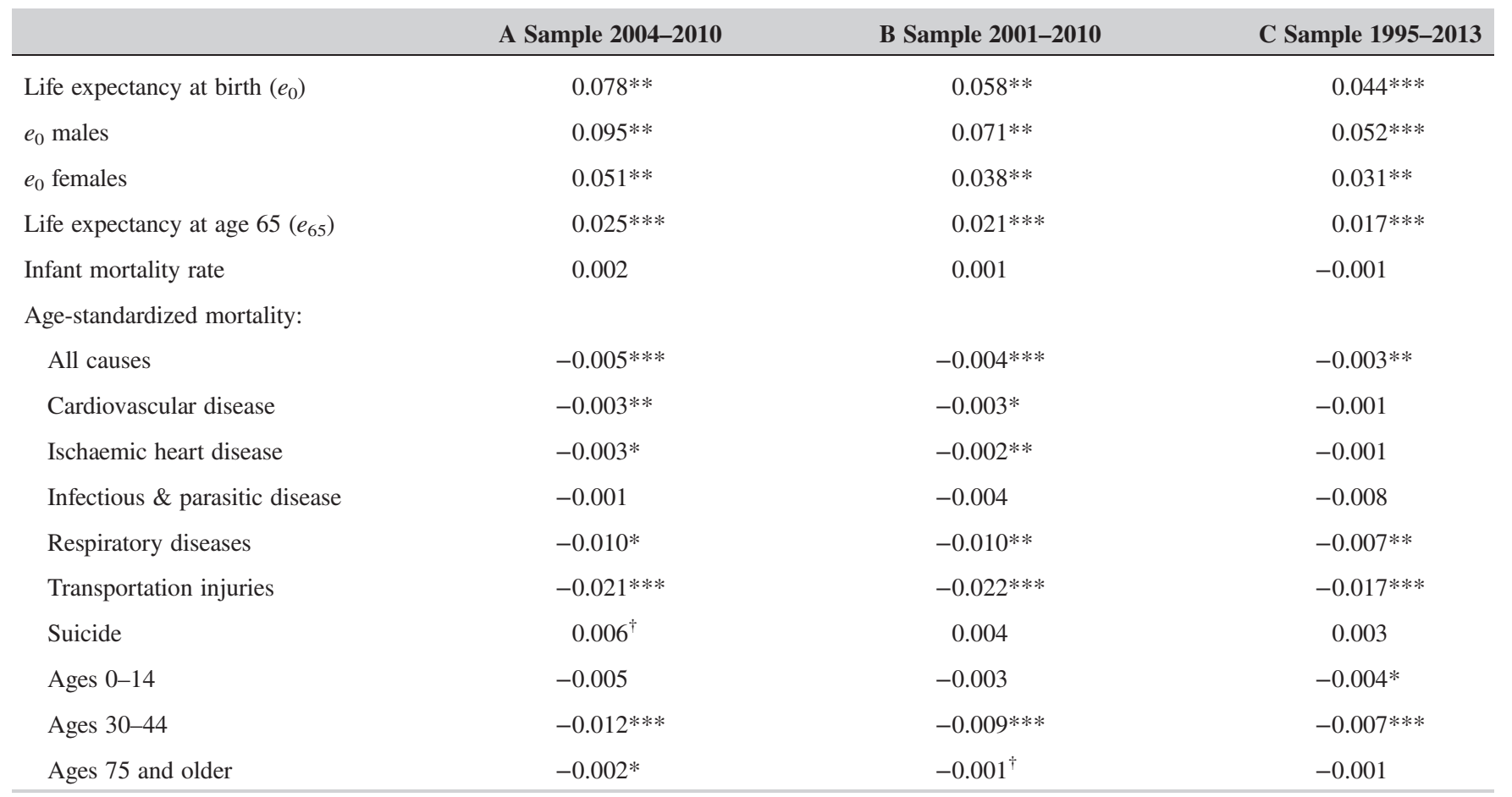

Note. The sample includes observations for Austria, Belgium, Bulgaria, Croatia, the Czech Republic, Denmark, Estonia, Finland, France, Germany, Greece, Hungary, Ireland, Italy, Latvia, Lithuania, Netherlands, Norway, Poland, Portugal, Romania, Slovakia, Slovenia, Spain, Sweden, Switzerland, and the UK. All estimates are based in regressions in which $e_{0}, e_{65}$, or the natural logarithm of a mortality rate is modeled as a function of a constant, the national unemployment rate, fixed effects for year and state, and country-specific linear trends, with observations weighted by the square root of the country's population. Because of missing data for particular years, countries, or health indicators, the number of observations included in the regressions was 176 in the sample 2004-2010, between 255 and 257 in the sample 2001-2010, and between 390 and 392 in the sample 1995-2013. Models are computed with robust standard errors adjusted for repeated observations in each country. The levels of statistical significance are indicated as follows.

$* p<.05$.

$* * p<.01$.

$* * * p<.001$

${ }^{\dagger} p<.1$.

computed weighting the observations by the square root of the population size, so that small countries do not have disproportionate influence, the correlations are reduced, but they are still highly significant $(0.52, p=.006$, for 2004-2007, and $0.74, p<.0001$, for 2007-2010). The scatter plot of $\Delta e_{0}$ and $\Delta U$ in 2007-2010 (Figure 5, bottom panel) may suggest that the Baltic states, Spain, and Ireland are outliers with undue influence in the high value of the correlation. However, suppressing the Baltic states, Spain, and Ireland, $r=0.58$ with the 22 unweighted observations and 0.59 when the observations are weighted by the square root of population ( $p=.004$ in both cases). These correlations are very supportive of the impression that, paradoxically, the more severe was the economic downturn, the greater was the increase in $e_{0}$ and, therefore, the decrease in mortality rates.

Sorting the 27 countries by the severity of the recession in three groups (Table 2), the changes before and after 2007 show that mortality rates that had been falling in 2004-2007 continued falling in 2007-2010. However, in the countries where the crisis was most severe (Table 2, Panel C), there were greater improvements in population health during the three years of recession than in the three previous years of economic expansion. Between 2007 and 2010, general mortality decreased $4.3 \%$ in the countries with mild recession, $6.4 \%$ in the group of countries where the crisis was moderate, and $10.5 \%$ in the countries where the crisis was most severe (Table 2). This gradient of health improvement in 2007-2010 correlated with the severity of the crises is also observable for $e_{0}\left(1.9,2.9\right.$, and 4.5), male $e_{0}\left(0.7,1.1\right.$, and 1.9), female $e_{0}(0.5,1.0$, and 1.4), mortality due to transportation injuries, infectious and parasitic diseases, and mortality at ages $0-14,30-44$, and $75+$. The mortality gradient is not observed for CVD, IHD, and respiratory disease, but for these three cause-specific mortality rates, the greatest reduction in 2007-2010 occurred in the group of countries in which the recession had been the most severe. Thus, considering multiple health indicators including general and sex-specific mortality as well as mortality due to major causes of 
TABLE 4 Estimate for the effect of the unemployment rate in regression models in which an indicator of population health is regressed on the national unemployment rate and a fixed effect for year, with both the dependent variable and the covariate detrended by subtracting a Hodrick-Prescott (HP) trend computed with a smoothing parameter $\gamma=6.25$ or $\gamma=100$

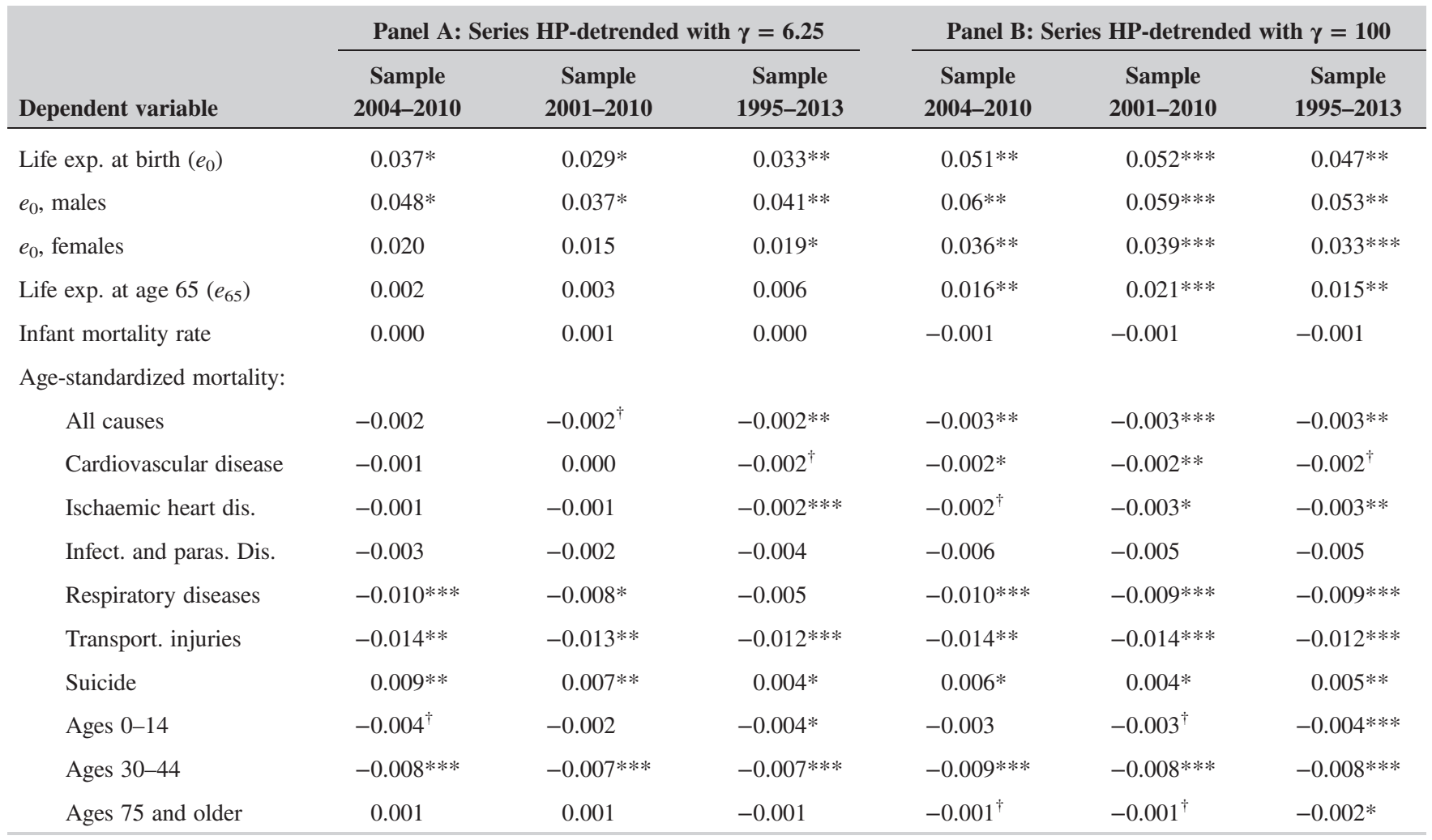

Note. The 27 countries included are those listed in Table 3 . All estimates are based in regressions in which a detrended series of a health indicator ( $\mathrm{e}_{0}$ or $\mathrm{e}_{65}$ in years, or the natural logarithm of a mortality rate) is modeled as a function of a constant, the detrended national unemployment rate and a fixed effect for year, with observations weighted by the square root of the country's population. Robust standard errors are computed considering autocorrelation in each country series. The number of observations included in the regressions was 189 for the 2004-2010 sample, 270 for the 2001-2010 sample, and between 486 and 491 for the $1995-2013$ sample.

$* p<.05$.

$* * p<.01$.

$* * * p<.001$.

${ }^{\dagger} p<.1$.

death, the largest improvement between 2007 and 2010 is observed in the countries where the severity of the recession was the highest.

Suicides depart from the pattern of most other mortality categories; as in the three groups of countries, they evolved better in 2004-2007 than in 2007-2010. But in the later recession years, suicides only increased in the countries where the recession was mild — where they increased by $0.2 \%$ —or moderate_-where they increased by $6.0 \%$ (Table 2, Panels A and B) —although surprisingly, they decreased by $1.6 \%$ in the countries where the recession was severe (Table 2, Panel C).

As measured by $e_{65}$ and mortality at ages 75 and older, mortality of the elderly improved more during the recession in countries most affected by the crisis (Table 2, Panel C), but improved more during the expansion years in the countries with mild or moderate recession.

The Baltic states, Spain, Greece, and Slovenia, where the recession has been the most severe (Figures 4 and 5 , bottom panel), had gains in $e_{0}$ that were greater in the 2007-2010 recession than in the 2004-2007 expansion (Table 1). The Baltic states are the extreme case. In the three of them, $e_{0}$ had a substantial gain of over 2.5 years in 2007-2010, but in two of them, Latvia and Lithuania, $e_{0}$ had decreased in 2004-2007 (Table 1, Figure 1). Germany and Austria are the only two countries in the sample in which unemployment rates did not increase between 2007 and 2010 (Figure 1, Table 1). However, in this period, these two countries performed poorly in terms of population health: $e_{0}$ increased in both 0.4 years, which is a third of Greece's gain and a seventh of Estonia's gain in the same 3-year period.

The descriptive evidence for 2004-2007 and 2007-2010 shows consistently that for most health indicators, changes in unemployment - which is an index of the severity of the crisis_correlate positively with improvements in health. 
Change in life expectancy at birth and the unemployment rate, 2004-2007

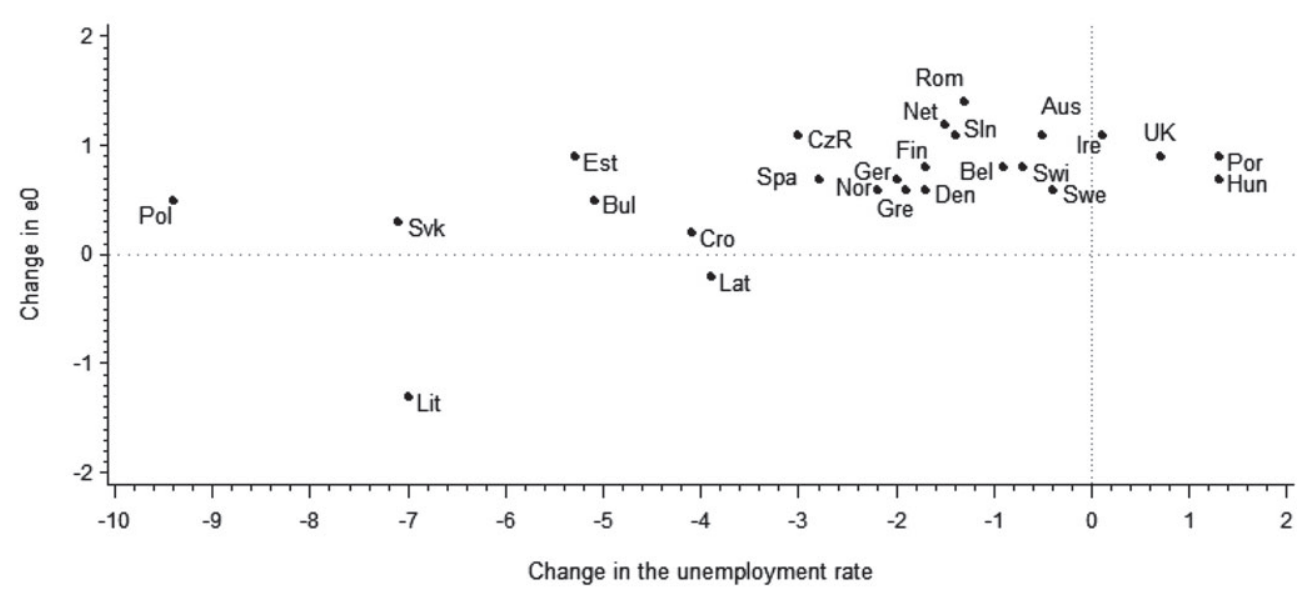

Change in life expectancy at birth and the unemployment rate, 2007-2010

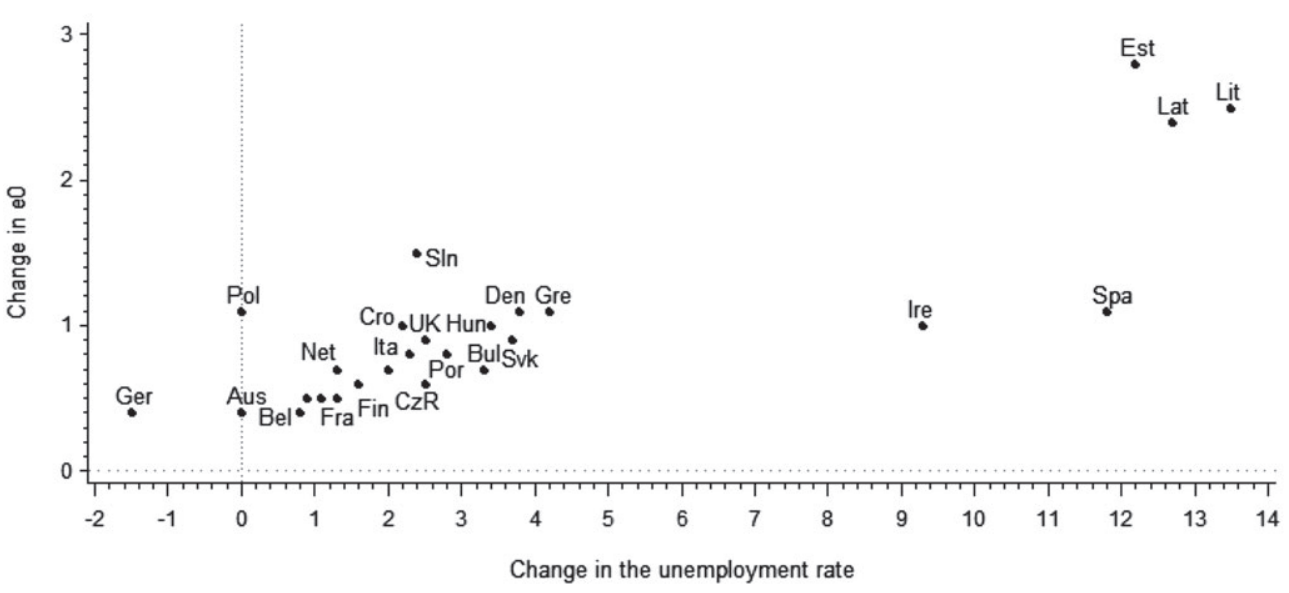

FIGURE 5 Changes in the unemployment rate and in life expectancy at birth $\left(e_{0}\right)$ in the 3-year periods before and after the start of the great recession

\section{5 | REGRESSION ANALYSIS}

Results of regressions computed with models like Equation 1, and a sample including the years 2004-2010 (Table 3, Panel A) show that rising unemployment is associated with general improvements in health indicators. Thus, an increase in the unemployment rate is associated with an increase in $e_{0}$ (for the general population as well as males and females) and $e_{65}$. A one-percentage point increase in unemployment was also associated with reductions of age-standardized mortality from all causes (by $0.5 \%$ ), from CVD (by $0.3 \%$ ), from IHD (by 0.3\%), from respiratory disease (by 1.0\%), from transportation injuries $(2.1 \%)$, and with a drop in mortality for ages $30-44$ (by $1.2 \%$ ) and for age $75+($ by $0.2 \%)$. When the sample is expanded to the years 2001-2010 (Table 3, Panel B) or to the period 1995-2013 (Table 3, Panel C), the effects are basically the same. The expansion of the sample tends to reduce the size of the effect though the levels of statistical significance are very similar. In the three samples, the effect estimate for suicides is positive, suggesting a level of suicides positively correlated with the unemployment rate, but in all samples, the effect is not statistically significant at the usual $95 \%$ level of confidence.

During the decade 2001-2010, the mean annual increase of $e_{0}$ was 0.27 years in our 27 country sample. Because our model shows that one percentage point increase in the unemployment rate is associated with an extra $e_{0}$ gain of 0.058 years (Table 3 ), a decrease of the unemployment rate by five percentage points or more will be associated with a reversal of the annual gain in $e_{0}$, as $0.27-5 \times 0.058=-0.02$. Thus, the models predict that a strong economic expansion in which unemployment falls by more than five percentage points will reverse the long-term rising trend in $e_{0}$, leading to a reduction of $e_{0}$. Apparently, this is what occurred in Lithuania and Latvia in the period 2004-2007 (Figures 2 and 5, top panel); when the economy boomed, unemployment decreased by several percentage points, and $e_{0}$ reversed its long-term decreasing trend. 
Models using nonlinear detrending (Table 4) of unemployment and mortality rates provide confirmation of the results obtained with linear detrending (Table 3). Using the HP filter for detrending either with a smoothing parameter $\gamma=100$ (Table 4, Panel B) or $\gamma=6.25$ (Table 4, Panel A), we found statistically significant effects consistent with a procyclical oscillation of mortality due to all causes, CVD, IHD, respiratory diseases, and transportation injuries. Similarly, positive and statistically significant effects of unemployment on $e_{0}$ (stronger for males) in the nonlinear models (Table 4) indicate a countercyclical oscillation of $e_{0}$ that is consistent with the procyclical oscillation of mortality rates. However, the link between the business cycle and mortality for all causes as well as $e_{65}$ and female $e_{0}$ appears clearly when the HP filter for nonlinear detrending is applied with $\gamma=100$ (Table 4, Panel B) and less so when it is applied with $\gamma=6.25$ (Table 4, Panel A). We believe that the HP filter applied with a smoothing parameter $\gamma=6.25$ eliminates to a substantial extent the oscillations corresponding to the so-called business cycle.

Although suicide appears acyclical or very weakly countercyclical using linear detrending (Table 3 of the paper), it appears clearly countercyclical in models using nonlinear detrending (Table 4), whatever the smoothing parameter used for the HP filter.

\section{6 | DISCUSSION}

The procyclical oscillation of mortality that had been found by different investigators using historical data of the United States (Eyer, 1977a; Ogburn \& Thomas, 1922; Ruhm, 2000; Tapia Granados \& Diez Roux, 2009) has appeared missing in some data for recent years (McInerney \& Mellor, 2012; Ruhm, 2015a), a finding that has generated some controversy (Lindo, 2015). What our results show, however, is that considering the most recently available data from Europe, there is outstanding evidence of a procyclical oscillation of mortality. We show that a procyclical oscillation of mortality is observable in the period 1995-2013 in Europe and in the period including the early years of the Great Recession and the previous expansion, no matter how we date them. We found that, as measured by a variety of major health indicators, population health in 2001-2010 evolved better during the recession than during the expansion, with the size of the annual improvement in population health being correlated with the increase in unemployment. As Gerdtham and Ruhm (2006) found in a panel of OECD countries, death rates tend to rise in periods of economic expansion so that, consistently with previous experience, in 2007-2010, there were major gains in health precisely in the countries where the crisis was more severe. Using as dependent variable $e_{0}, e_{65}$, total mortality and cause-specific mortality for CVD, IHD, respiratory disease, and transportation injuries, we found evidence of a procyclical oscillation of mortality that is consistent across regression models (Tables 3 and 4, Tables B1 and B2 in Appendix B). With very few exceptions, our analyses with different model specifications and subsamples show that the deterioration of macroeconomic conditions indexed by the increase in the unemployment rate is correlated with improvements in health indicators. Our analyses do not suggest a significant relation of infant mortality and mortality at ages $0-14$ with the fluctuations of the economy.

Our results are robust to the selection of variable to weight the observations in the regression as well as to the selection of economic indicator to be used as business cycle indicator (Tables 3 and 4). Models in which the economy is indexed by the unemployment rate are better to reveal the procyclical oscillation of death rates, as standard errors are smaller and levels of significance higher. Nevertheless, we find macroeconomic effects on mortality in the same direction when using as economic indicator the employment-to-population ratio (Table B1, Appendix B), or GDP per capita (Table B1, Appendix B), which is the economic indicator that performs worst to reveal the macroeconomic effect on mortality. In all specifications and models, mortality rates at middle age (30-44) and advanced age (75+) show a clear procyclical oscillation. However, mortality at ages 30-44 is more responsive to macroeconomic change, and the effect appears systematically in all models (Tables 3 and 4, Table B1 in Appendix B). This contrasts with some claims that in the United States, procyclical mortality is mostly a phenomenon of advanced ages (Miller et al., 2009; Stevens et al., 2011).

Because the present investigation has focused on a reduced time, we did not try to study lagged effects. It might be worth mentioning, though, that findings of lagged harmful effects of recessions on health reported in the past by Brenner (1983) have never been confirmed by other researchers (Tapia Granados, 2012; Tapia Granados \& Ionides, 2008; Wagstaff, 1985; Winter, 1983). Brenner's studies have received a variety of criticisms (Cook \& Zarkin, 1986; Eyer, 1977b; Kagan, 1987; Kasl, 1979; Ruhm, 2006, 2008; Wagstaff, 1985) that have led to considerable skepticism about Brenner's data and conclusions (Kasl \& Jones, 2000).

Our results for suicides are inconclusive and somewhat surprising. Many studies have found suicides fluctuating countercyclically, that is, increasing in recessions, in different countries and periods (Waldron \& Eyer, 1975; Eyer, 1977a; Boor, 1980; Bollen, 1983; Plaut \& Anderson, 1999; Ruhm, 2000; Tapia Granados, 2005, 2008; Khang, Lynch, \& Kaplan, 2005; 
Tapia Granados \& Diez Roux, 2009; Luo et al., 2011; Ionides et al., 2013; Chang, Stuckler, Yip, \& Gunnel, 2013). Indeed, focusing on morbidity rather than mortality, Ruhm (2005) found that in the United States, mental health tends to be procyclical, whereas physical health is countercyclical (Ruhm, 2005). This would be consistent with a countercyclical oscillation of suicides and a procyclical oscillation of deaths due to physical ailments such as heart attacks, respiratory diseases, or physical injuries. However, some investigations on suicides in European countries found suicides oscillating procyclically, increasing in expansions, in Finland (Hintikka et al., 1999) and in Germany (Neumayer, 2004), and unrelated to the business cycle in Sweden (Tapia Granados \& Ionides, 2011), and there has been disagreement on whether suicides in the Baltic states have increased significantly during the Great Recession (Reeves et al., 2012; Reeves et al., 2013; Stankunas et al., 2013). In our investigation, the increase in suicides associated with higher levels of unemployment is not statistically significant in most models and samples. Our main model (Table 3) shows no significant relation of suicides with macroeconomic conditions at the usual levels of confidence. However, we find a significant countercyclical fluctuation of suicides in the models with variables detrended by nonlinear methods (Table 4).

The size of the macroeconomic effect on mortality that we report is similar to what was found in previous investigations. With 2004-2010 data, we found that a one percentage point increase in the national unemployment rate is associated with a $0.5 \%$ decrease in mortality; the effect goes down to $0.4 \%$ and $0.3 \%$, respectively, with 2001-2010 data and with 19952013 data (Table 3). These effects are very similar to the $0.5 \%$ and $0.4 \%$ mortality reductions per percentage point increase in unemployment that were respectively found by Ruhm (2000) with 1972-1991 data from the states of the USA and by Gerdtham and Ruhm (2006) in a 1960-1997 panel of 23 OECD countries. However, Toffolutti and Suhrcke (2014) reported much larger effects. Considering mortality at ages below 65 and using a 2003-2010 panel for 23 European Union countries, Toffolutti and Suhrcke found a one percentage point increase in the national unemployment rate was associated at high levels of statistical significance with a 3.4\% decrease in age-adjusted mortality for ages below 65, a 3.7\% reduction of mortality due to CVD, a $11.5 \%$ reduction of mortality due to motor vehicle traffic injuries, and a $4.1 \%$ increase of suicides. Considering mortality at all ages, we found associations in the same direction but with a $0.4 \%$ reduction of CVD mortality $(p<.001)$, a $2.2 \%$ reduction in traffic mortality $(p<.001)$, and a $0.7 \%$ marginally significant increase of suicides $(p=.069)$. Thus, the always highly significant effect estimates of Toffolutti and Suhrcke are between five and eight times bigger than ours, which does not seem to be justified by the difference in dependent variable (all ages mortality for us and mortality at ages below 65 for them).

We have also tried to replicate Toffolutti and Suhrcke's results for all-cause mortality at ages below 65 by fitting models as close as possible to the one reported by Toffolutti and Suhrcke. The effect estimates we found were around $-1.0 \%$, that is, between three and four times smaller than Toffolutti and Suhrcke's estimate.

Our conclusion is that Toffolutti and Suhrcke's outsized effects always at high levels of statistical significance may be due to a numerical mistake or a misspecification of the model. ${ }^{2}$

Considering long-run trends, since the 19th century, age-specific mortality rates have declined, whereas GDP per capita has increased in every country. Overall, throughout time, higher levels of GDP per capita are generally associated with lower levels of mortality and higher levels of $e_{0}$. This has promoted the view that "wealthier is healthier" (Pritchett \& Summers, 1996), that increasing levels of income are always associated to increased levels of health. However, the distribution of $e_{0}$ and GDP per capita in different decades of the 20th century led Samuel Preston to conclude that only a minor part of past gains in $e_{0}$-about $20 \%$ - could be attributed to rising income (Preston, 1976, 1996). Cross-country data show "almost no relation between changes in life expectancy and economic growth over 10, 20, or 40-year time periods between 1960 and 2000," so that in many countries, there have been "remarkable improvements in health with little or no economic growth" (Cutler et al., 2006). Amartya Sen found that the rate of decline of mortality in Britain between 1900 and 1970 revealed an inverse relationship with economic growth, with decades of high-economic growth associated with low increases in life expectancy (Sen, 2001), a relation that is also found for most of the 20th century in a year-to-year analysis (Tapia Granados, 2012). For Samuel Preston, to obtain gains in health levels no longer requires economic growth (Preston, 2007). This idea is quite difficult to accept for some researchers (Mackenbach, 2007), but it is quite consistent with the results of this investigation, which adds the recent European experience to the body of literature showing that, in the short run, economic recessions are rather beneficial for a variety of health outcomes. This well-documented historical phenomenon has been reported to be weakening in recent years in the United States (Ruhm, 2013), as well as in recent years in other countries (Tapia Granados, 2008, 2012)

\footnotetext{
${ }^{2}$ Toffolutti and Suhrcke's model includes the logarithm of real GDP per capita as covariate. The inclusion of this variable that is strongly correlated with the unemployment rate (both are business cycle indicators) potentially complicates the interpretation of the coefficient for unemployment. At any rate, in our attempts to replicate Toffolutti and Suhrcke's model, we find the effect of GDP per capita not statistically significant, and both including or excluding it from the model, we get estimates of around $-1.0 \%$ for the unemployment rate effect on mortality, much smaller than Toffolutti and Suhrcke's estimates.
} 
but apparently remains evident in recent years when the overall experience of the European countries since 2000 is considered.

The association of faster reductions in mortality with rising unemployment when there is an economic downturn is counterintuitive because it is at odds with research that has shown (a) that compared with employed, unemployed individuals have worse health outcomes and (b) that there is a strong health gradient by social class, so that higher income correlates with better health. In recessions, joblessness increases and income declines for most people. Others thing being equal, we should then expect that mortality increased in recessions or at least that it decreased less the more severe is the downturn. However, what we observe is that mortality accelerates its declining trend when the economy slows down. The explanation must be that other things are not equal, and some important determinants of ill health and death are correlated with economic activity. For trafficrelated mortality, the cyclical mechanism seems quite apparent, because economic downturns reduce industrial and commercial traffic, as well as commuting and recreational driving. Expansions also bring overtime hours and higher intensity of work, as well as hiring of new workers who are inexperienced and more prone to industrial injuries. Another explanation of procyclical death rates is atmospheric pollution, which rises in expansions and falls in recessions (Davis, Laden, Hart, Garshick, \& Smith, 2010). We found a significant positive correlation of the decline in respiratory mortality with the severity of the recession in 2007-2010 (Table 2), and in the panel 2001-2010, one percentage point increase in the unemployment rate is associated with a 1.0\% reduction in respiratory disease mortality (Table 3, Panel B). In countries where the crisis has been severe, respiratory disease mortality dropped by $16.1 \%$ in 2007-2010 and just by 3.2\% in 2004-2007 (Table 2). Thus, atmospheric pollution seems a key mechanism linking macroeconomic fluctuations with mortality through respiratory disease and CVD deaths. This is consistent with the fact that daily hospitalizations and deaths due to acute respiratory or cardiovascular ailments increase when atmospheric pollution is higher (Dominici et al., 2006; Jerrett et al., 2005; Lisabeth et al., 2008; Pope \& Dockery, 2006; Schwartz, 1994). For Heutel and Ruhm (2013), procyclical atmospheric pollution explains about a third of the procyclical oscillation of mortality in the United States.

Other potential mechanisms linking macroeconomic swings with mortality oscillations are work environment factors, with slower rhythms of work and less overtime leading to less occupational stress and more time for sleep, physical activity, and social interaction, which is health promoting (Biddle \& Hamermesh, 1990; Edwards, 2011; Eyer, 1977a, 1980; Sterling \& Eyer, 1981, 1988). More commuting and internal migration resulting from upturns in business activity might lead to an enhanced circulation of pathogens (Ionides et al., 2013). More frequent mild infections and higher pollution would increase the risk of acute cardiorespiratory events in persons carrying CVD or respiratory chronic disease (Ruhm, 2008). Social isolation and cigarette smoking also increase in expansions and decrease in recessions (Edwards, 2011; Gerdtham \& Ruhm, 2006; Xu, 2013) and may also be contributors to the increased risk of death in economic expansions.

Migration causing unaccounted changes in the national population can change mortality rates, but this would be an unlikely explanation for the changes in the age-adjusted health indicators we have used in this investigation, that according to WHO are reasonably comparable for the countries in our sample (WHO Regional Office for Europe 2016a, Technical Notes). Furthermore, the sizable gains in population health during the recession years are observed in countries like Ireland or Spain, which had sustained population growth throughout the decade, but also in countries like the Baltic states, which had sustained population decline between 2001 and 2010 (Table B3, Appendix B). The consistency of our results for males and females and across mid and advanced ages also reduces the credibility of the hypothesis that our results can be determined by population displacements.

According to WHO estimates (WHO Regional Office for Europe, 2016a), total health expenditure measured as percentage of GDP had a marked peak in 2009 in most European countries, with substantial drops between 2009 and 2010 in Austria, Czech Republic, France, Germany, Greece, Ireland, Lithuania, Poland, Portugal, Slovakia, Slovenia, Spain, Sweden, and Switzerland. Total health expenditure, measured in units of purchasing power parity per capita, peaked in Latvia in 2007, in Ireland and in Lithuania in 2008, and in most other countries of our sample in 2009 (Figures B1 and B2, Appendix B). Thus, we found large gains in population health in 2007-2010 in Greece, Slovakia, Spain, and the Baltic states, where the recession has been the most severe and austerity policies have been applied at least from 2009. In Latvia, when major health expenditure cuts took place between 2007 and 2010, there was a gain of 2.5 years in $e_{0}$, whereas $e_{0}$ decreased by a tenth of a year in 2004-2007, when the economy was booming and health spending was quickly increasing. All this evidence does not seem compatible with recent claims that reductions in health spending have had major harmful effects on population health (Karanikolos et al., 2013; Stuckler \& Basu, 2013). Besides health spending being cut, the provision and the quality of health care services may have deteriorated in many European countries in which austerity policies have been applied (García Rada, 2012; Kondilis et al., 2013; Pavolini \& Guillén, 2013). If that is the case, as very likely is, our findings suggest that a substantial deterioration in health care may not have a short-run effect on mortality (McKinlay, McKinlay, \& Beaglehole, 1989). 


\section{ACKNOWLEDGEMENTS}

We are grateful to several reviewers who provided helpful comments on previous versions of this paper.

\section{REFERENCES}

Abdala, F., Geldstein, R. N., \& Mychaszula, S. M. (2000). Economic restructuring and mortality changes in Argentina-Is there any connection? In G. A. Cornia, \& R. Paniccià (Eds.), The mortality crisis in transitional economies. (pp. 328-350). New York: Oxford University Press.

Biddle, J. E., \& Hamermesh, D. S. (1990). Sleep and the allocation of time. Journal of Political Economy, 98, 922-943.

Bollen, K. A. (1983). Temporal variation in mortality: A comparison of US suicides and motor vehicle fatalities 1972-1976. Demography, 20 , 45-59.

Boor, M. (1980). Relationship between unemployment rates and suicide rates in eight countries, 1962-1976. Psychological Reports, 47, 1089-1101.

Brenner, M. H. (1983). Mortality and economic instability: Detailed analyses for Britain and comparative analyses for selected industrialized countries. International Journal of Health Services, 13(4), 563-620.

Burgard, S. A., Brand, J. E., \& House, J. S. (2009). Perceived job insecurity and worker health in the United States. Social Science \& Medicine, 69(5), 777-785.

Catalano, R., Goldman-Mellor, S., Saxton, K., Margerison-Zilko, C., Subbaraman, M., LeWinn, K., \& Anderson, E. (2011). The health effects of economic decline. Annual Review of Public Health, 32, 431-450.

Chang, S., Stuckler, D., Yip, P., \& Gunnel, D. (2013). Impact of 2008 global economic crisis on suicide: Time trend study in 54 countries. BMJ, 347(f5239), 1-15.

Cook, P. J., \& Zarkin, G. A. (1986). Homicide and economic conditions: A replication and critique of M. Harvey Brenner's new report to the U.S. congress. Journal of Quantitative Criminology, 2(1), 69-80.

Cornia, G. A., \& Paniccià, R. (Eds) (2000). The mortality crisis in transitional economies. New York: Oxford University Press.

Cutler, D. M., Deaton, A., \& Lleras-Muney, A. (2006). The determinants of mortality. Journal of Economic Perspectives, 20(3), 97-120.

Davis, M. E., Laden, F., Hart, J. E., Garshick, E., \& Smith, T. J. (2010). Economic activity and trends in ambient air pollution. Environmental Health Perspectives, 118(5), 614-619.

de la Fuente, V. S., Camino López, M. A., González, I. F., González Alcántara, O. J., \& Ritzel, D. O. (2014). The impact of the economic crisis on occupational injuries. Journal of Safety Research, 48(2), 77-85.

Diggle, P. J. (1989). Time series: A biostatistical introduction. New York: Oxford University Press.

Dominici, F., Peng, R. D., Bell, M. L., Pham, L., McDermott, A., Zeger, S. L., \& Samet, J. M. (2006). Fine particulate air pollution and hospital admission for cardiovascular and respiratory diseases. JAMA, 295(10), 1127-1134.

Edwards, R. D. American time use over the business cycle. Paper presented to the 2011 Annual meeting of the PAA, Washington, DC, 2011.

Eyer, J. (1977a). Prosperity as a cause of death. International Journal of Health Services, 7(1), 125-150.

Eyer, J. (1977b). Does unemployment cause death rate peak in each business-cycle? Multifactor model of death rate change. International Journal of Health Services, 7(4), 625-662.

Eyer, J. (1980). Social causes of coronary heart-disease. Psychotherapy and Psychosomatics, 34(2-3), 75-87.

García Rada, A. (2012). Primary care in Spain is underfunded and unattractive, says report. BMJ, 344(04/03).

Gerdtham, U. G., \& Ruhm, C. J. (2006). Deaths rise in good economic times: Evidence from the OECD. Economics and Human Biology, 4(3), 298-316.

Gonzalez, F., \& Quast, T. (2010a). Macroeconomic changes and mortality in Mexico. Empirical Economics, 40(2), 305-319.

Gonzalez, F., \& Quast, T. (2010b). Mortality and business cycles by level of development: Evidence from Mexico. Social Science \& Medicine, 71(12), 2066-2073.

Gujarati, D. N. (2003). Basic econometrics (4th ed.). New York: McGraw-Hill.

Haaland, V. F., \& Telle, K. (2015). Pro-cyclical mortality across socioeconomic groups and health status. Journal of Health Economics, 39, $248-258$.

Heutel, G., \& Ruhm, C. J. (2013). Air pollution and procyclical mortality. NBER Working Paper 18958.

Hintikka, J., Saarinen, P. I., \& Viinamäki, H. (1999). Suicide mortality in Finland during an economic cycle, 1985-1995. Scandinavian Journal of Public Health, 27(2), 85-88.

Ionides, E., Wang, Z., \& Tapia Granados, J. A. (2013). Macroeconomic effects on mortality revealed by panel analysis with nonlinear trends. Annals of Applied Statistics, 7(3), 1362-1385.

Jerrett, M., Burnett, R. T., Ma, R., Pope, 3rd C. A., Krewski, D., Newbold, K. B., ... Thun, M. J. (2005). Spatial analysis of air pollution and mortality in Los Angeles. Epidemiology 16(6), 727-736.

Kagan, A. R. (1987). Unemployment causes ill health: The wrong track. Social Science \& Medicine, 25(2), 217-218. 
Karanikolos, M., Mladovsky, P., Cylus, J., Thomson, S., Basu, S., Stuckler, D., .. McKee, M. (2013). Financial crisis, austerity, and health in Europe. Lancet, 381(9874), 1323-1331.

Kasl, S. (1979). Mortality and the business cycle: Some questions about research strategies when utilizing macro-social and ecological data. American Journal of Public Health, 69(8), 784-789.

Kasl, S. V., \& Jones, B. A. (2000). The impact of job loss and retirement on health. In L. F. Berkman, \& I. Kawachi (Eds.), Social epidemiology. (pp. 118-136). New York: Oxford University Press.

Kentikelenis, A., Karanikolos, M., Reeves, A., McKee, M., \& Stuckler, D. (2014). Greece's health crisis: From austerity to denialism. Lancet, 383(9918), 748-753.

Khang, Y. H., Lynch, J. W., \& Kaplan, G. A. (2005). Impact of economic crisis on cause-specific mortality in South Korea. International Journal of Epidemiology, 34(6), 1291-1301.

Kondilis, E., Giannakopoulos, S., Gavana, M., Ierodiakonou, I., Waitzkin, H., \& Benos, A. (2013). Economic crisis, restrictive policies, and the population's health and health care: The Greek case. American Journal of Public Health, 103(6), 973-979.

Kose, M. A., \& Terrones, M. E. (2015). Colapse and revival: Understanding global recessions and recoveries. Washington, DC: IMF.

Liaropoulos, L. (2012). Greek economic crisis: Not a tragedy for health. BMJ, 345, e7988.

Lin, S.-J. (2009). Economic fluctuations and health outcome: A panel analysis of Asian-Pacific countries. Applied Economics, 41, 519-530.

Lindo, J. M. (2015). Aggregation and the estimated effects of economic conditions on health. Journal of Health Economics, 40, 83-96.

Lisabeth, L. D., Escobar, J. D., Dvonch, J. T., Sanchez, B. N., Majersik, J. J., Brown, D. L., ... Morgenstern, L. B. (2008). Ambient air pollution and risk for ischemic stroke and transient ischemic attack. Annals of Neurology, 64(1), 53-59.

Luo, F., Florence, C., Quispe-Agnoli, M., Ouyang, L., \& Crosby, A. (2011). Impact of business cycles on US suicide rates, 1928-2007. American Journal of Public Health, 101(6), 1139-1146.

Mackenbach, J. P. (2007). Commentary: Did Preston underestimate the effect of economic development on mortality? International Journal of Epidemiology, 36(3), 496-497; 502-503.

Martikainen, P. T., \& Valkonen, T. (1996). Excess mortality of unemployed men and women during a period of rapidly increasing unemployment. Lancet, 348(9032), 909-914.

McInerney, M., \& Mellor, J. M. (2012). Recessions and seniors' health, health behaviors, and healthcare use: Analysis of the Medicare current beneficiary survey. Journal of Health Economics, 31(4), 744-751.

McKinlay, J. B., McKinlay, S. M., \& Beaglehole R. (1989). Trends in death and disease and the contribution of medical measures. In H. E. Freeman \& S. Levine (Eds.), Handbook of medical sociology, (2nd ed.), (pp 14-45). Englewood Cliffs, NJ: Prentice Hall.

Miller, D. L., Page, M. E., Stevens, A. H., \& Filipski, M. (2009). Why are recessions good for your health? American Economic Review, 99(2), 122-127.

Neumayer, E. (2004). Recessions lower (some) mortality rates: Evidence from Germany. Social Science and Medicine, 58, 1037-1047, and 59:1993.

Ogburn, W. F., \& Thomas, D. S. (1922). The influence of the business cycle on certain social conditions. Journal of the American Statistical Association, Reprinted with Commentaries, International Journal of Epidemiology, 201618, 324-340.

Pavolini, E., \& Guillén, A. M. (Eds) (2013). Health care systems in Europe under austerity: Institutional reforms and performance. London: Palgrave Macmillan.

Plaut, E. A., \& Anderson, K. (Eds) (1999). Marx on suicide. Evanston, Ill: Northwestern University Press.

Pope, C. A. 3rd, \& Dockery, D. W. (2006). Health effects of fine particulate air pollution: Lines that connect. Journal of the Air \& Waste Management Association, 56, 709-742.

Preston, S. H. (1976). Mortality patterns in national populations. New York: Academic Press.

Preston, S. H. (1996). Population studies of mortality. Population Studies, 50, 525-536.

Preston, S. H. (2007). Response: On the changing relation between mortality and level of economic development'. International Journal of Epidemiology, 36(3), 502-503.

Pritchett, L., \& Summers, L. H. (1996). Wealthier is healthier. Journal of Human Resources, 31(4), 841-868.

Reeves, A., Stuckler, D., McKee, M., Gunnell, D., Chang, S. S., \& Basu, S. (2012). Increase in state suicide rates in the USA during economic recession. Lancet, 380(9856), 1813-1814.

Reeves, A., Stuckler, D., McKee, M., Gunnell, D., Chang, S. S., \& Basu, S. (2013). Suicide, recession, and unemployment—Authors' reply. Lancet, 381(9868), 722.

Regidor, E., Vallejo, F., Tapia Granados, J. A., Viciana-Fernández, F. J., Fuente, L., \& Barrio, G. (2016). Faster mortality decline in low socioeconomic groups during the economic crisis in Spain: A cohort study of 36 million people. Lancet, 388, 2642-2652.

Riley, J. C. (2001). Rising life expectancy: A global history. New York: Cambridge University Press.

Rolden, H. J. A., van Bodegom, D., van den Hout, W. B., \& Westendorp, R. G. J. (2014). Old age mortality and macroeconomic cycles. Journal of Epidemiology and Community Health, 68(1), 44-50. 
Ruhm, C. J. (2000). Are recessions good for your health? Quarterly Journal of Economics, 115(2), 617-650.

Ruhm, C. J. (2005). Healthy living in hard times. Journal of Health Economics, 24(2), 341-363.

Ruhm, C. J. (2006). Macroeconomic conditions, health, and mortality. In A. M. Jones (Ed.), The Elgar companion to health economics). Cheltenham, UK: Edward Elgar.

Ruhm, C. J. (2007). A healthy economy can break your heart. Demography, 44(4), 829-848.

Ruhm, C. J. (2008). Macroeconomic conditions, health, and government policy. In R. F. Schoeni, J. S. House, G. Kaplan, \& H. Pollack (Eds.), Making Americans healthier: Social and economic policy as health policy. New York: Russell Sage.

Ruhm, C. J. (2013). Recessions, healthy no more? NBER Working Paper No. 19287. Cambridge, MA: National Bureau of Economic Research.

Ruhm, C. J. (2015a). Recessions, healthy no more? Journal of Health Economics, 42, 17-28.

Ruhm, C. J. (2015b). Health effects of economic crises. NBER Working Paper 21604. Available at www.nber.org/papers/w21604.

Schwartz, J. (1994). Air pollution and daily mortality: A review and meta-analysis. Environmental Research, 64(1) Jan, 36-52.

Sen, A. (2001). Economic progress and health. In D. Leon, \& G. Walt (Eds.), Poverty, inequality, and health: An international perspective. (pp. 333-345). Oxford: Oxford University Press.

Simou, E., \& Koutsogeorgou, E. (2014). Effects of the economic crisis on health and healthcare in Greece in the literature from 2009 to 2013: A systematic review. Health Policy, 115(4), (2-3)111-119.

Stankunas, M., Lindert, J., Avery, M., \& Sorensen, R. (2013). Suicide, recession, and unemployment (letter). Lancet, 381 (9868), 721.

Sterling, P., \& Eyer, J. (1981). Biological basis of stress-related mortality. Social Science \& Medicine, 15(1), 3-42.

Sterling, P., \& Eyer, J. (1988). Allostasis: A new paradigm to explain arousal pathology. In S. Fisher, \& J. Reason (Eds.), Handbook of life stress, cognition and health). Chichester; New York: Wiley.

Stevens, A. H., Miller, D. L., Page, M. E., \& Filipski, M. (2011). The best of times, the worst of times: Understanding pro-cyclical mortality (NBER working paper no. w17657). Cambrdge, Mass.: National Bureau of Economic Research.

Stuckler, D., \& Basu, S. (2013). The body economic: Why austerity kills. New York: Basic Books.

Sullivan, D., \& von Wachter, T. (2009). Job displacement and mortality: An analysis using administrative data. Quarterly Journal of Economics, 124(3), 1265-1306.

Szreter, S., \& Mooney, G. (1998). Urbanization, mortality, and the standard of living debate: New estimates of the expectation of life at birth in nineteenth-century British cities. Economic History Review, 51(1), 84-112.

Tapia Granados, J. A. (2005). Increasing mortality during the expansions of the US economy, 1900-1996. International Journal of Epidemiology, 34(6), 1194-1202.

Tapia Granados, J. A. (2008). Macroeconomic fluctuations and mortality in postwar Japan. Demography, 45(2), $323-343$.

Tapia Granados, J. A. (2012). Economic growth and health progress in England and Wales: 160 years of a changing relation. Social Science \& Medicine, 74(5), 688-695.

Tapia Granados, J. A., \& Diez Roux, A. V. (2009). Life and death during the Great Depression. Proceedings of the National Academy of Sciences of the USA, 106, 17290-17295.

Tapia Granados, J. A., \& Ionides, E. L. (2008). The reversal of the relation between economic growth and health progress: Sweden in the 19th and 20th centuries. Journal of Health Economics, 27(3), 544-563.

Tapia Granados, J. A., \& Ionides, E. L. (2011). Mortality and macroeconomic fluctuations in contemporary Sweden. European Journal of Population, 27(2), 157-184.

Tapia Granados, J. A., \& Rodriguez, J. M. (2015). Health, economic crisis, and austerity: A comparison of Greece, Finland and Iceland. Health Policy, $119(7), 941-953$.

Tapia Granados, J. A., House, J. S., Ionides, E. L., Burgard, S. A., \& Schoeni, R. F. (2014). Individual joblessness, contextual unemployment, and mortality risk. American Journal of Epidemiology, 180(3), 280-287.

Toffolutti, V., \& Suhrcke, M. (2014). Assessing the short term health impact of the Great Recession in the European Union: A cross-country panel analysis. Preventive Medicine, 64(7), 54-62.

Valkonen, T., \& Martikainen, P. T. (1996). The association between unemployment and mortality: Causation or selection? In A. D. Lopez, G. Casell, \& T. Valkonen (Eds.), Adult mortality in developed countries: From description to explanation. (pp. 1859-1861). Oxford: Clarendon Press.

Wagstaff, A. (1985). Time series analysis of the relationship between unemployment and mortality: A survey of econometric critiques and replications of Brenner's studies. Social Science \& Medicine, 21(9), 985-996.

Waldron, I., \& Eyer, J. (1975). Socioeconomic causes of the recent rise in death rates for 15-24 year-olds. Social Science and Medicine, 9(7), 383-396.

WHO Regional Office for Europe (2016a). European Health For All Database HFA-DB. Available from http://www.euro.who.int/hfadb. 
WHO Regional Office for Europe (2016b). Mortality Database HFA-MDB. Available from http://www.euro.who.int/en/data-and-evidence/databases/ mortality-indicator-database-mortality-indicators-by-67-causes-of-death,-age-and-sex-hfa-mdb.

Winter, J. (1983). Unemployment, nutrition and infant mortality in Britain, 1920-50. In The working class in modern British history: Essays in honour of Henry Pelling). Cambridge: Cambridge University Press.

World Bank. (2016). World Development Indicators (WDI). Available from data.worldbank.org/data-catalog/world-development-indicators.

Xu, X. (2013). The business cycle and health behaviors. Social Science \& Medicine, 77, 126-136.

\section{Supporting Information}

Additional Supporting Information may be found online in the supporting information tab for this article.

How to cite this article: Tapia Granados JA, Ionides EL. Population health and the economy: Mortality and the Great Recession in Europe. Health Economics. 2017;26:e219-e235. https://doi.org/10.1002/hec.3495 